\title{
Irish media: slow to get up to the pace of the game
}

\author{
John Greene \\ Sunday Independent sports editor
}

(C) John Greene. This work is licensed under the Creative Commons Attribution-NonCommercial-

NoDerivatives 4.0 International License. To view a copy of this license, visit

http://creativecommons.org/licenses/by-nc-nd/4.0/.

\begin{abstract}
This piece reflects on my professional and personal involvement in sport, as editor of a national newspaper and coach of a girls' youth team at my local GAA club. In so doing, it highlights some of the prejudices I saw first-hand while coaching teams which, in turn, opened my eyes to my own failures in my role as sports editor. The first camogie supplement in a Sunday newspaper sports section broke this glass ceiling. Arguably, the responsibility on native media outlets to include more coverage of women's sports is increasing as mainly UK broadcasters enter the Irish media scape.
\end{abstract}

Keywords: Sport; Women, Media; Newspapers; Gender; Disparity

On September 11, 2016, the Sunday Independent published a four-page supplement on the All-Ireland camogie finals to be played that day. The supplement was wrapped around the newspaper's sports section, highlighting it as a fitting recognition of an important day in the Irish sporting calendar.

Just over 20,000 people attended the three finals - senior, intermediate and premier junior - in Croke Park, an increase of over 20 per cent on the previous year and the biggest attendance since 2009, when the senior final was a double-header with the All-Ireland under 21 hurling final. The supplement may not have led directly to this increase but it certainly increased awareness of the event.

The production was a collaboration between the paper and the Camogie Association. It contained a mixture of content provided by the paper's own editorial team and by the Camogie Association, so in a way it was an inventive solution to a basic issue within the media - a lack of knowledge, and resources, around women's sport. This has been at the heart of the failure of women's sport to make inroads into the inherent biases of key decision makers in Ireland's national media. Too many people in positions of power in the media knew too little about the sporting landscape occupied by women.

There was another significant barrier. Two years ago, I spent some time going through the archives of the Sunday Independent's sports section, compiling a selection of articles over a 30-year span for a book. It was striking as I did so to see how long it took for women to become more of a presence in the world of sports writing. The situation has certainly improved, but the imbalance remains quite pronounced. There is still a way to go to attain the same kind of representation in sports writing as there is in other areas of the media. 
Sports writing remains largely male dominated, even if there is a greater awareness now about the domain of female sports, and a greater willingness to pursue stories and features. That, obviously, wasn't always the case.

So, while the reasons behind the gender disparity in sport at all levels have been well thrashed out in recent years, it's important to acknowledge the presence of these obstacles because they had a direct bearing on how much (or little) women's sport featured in mainstream media. Furthermore, how sport had always been portrayed, with its celebration of masculinity and machismo, had only served to deepen the gender divide. The clash of the Titans. The battle of the giants. May the best man win . . the language and the imagery was generally tilted in one direction. (There were exceptions, most notably around some individually brilliant female athletes like Sonia O'Sullivan and Catherina McKiernan, who were stars on the world stage. Until quite recently, though, there was no sense in the media of the world of female sport and the day-to-day goings on for many in team and individual events.)

As proud as I was of that first supplement, it also brought home to me that it was something that could have happened - indeed should have happened - before 2016. The biggest failure in this regard was a failure of imagination. It took the Camogie Association posing a question to start the ball rolling: What more can we do to increase awareness of our games? And then, asking me a question: What more can we do to help you increase awareness of our games?

The penny should have dropped sooner. Five years earlier I had started training a group of girls in my local GAA club. We had noticed that there was an unusually high number of girls aged between 10 and 12 playing football, but although the club was fielding a mixed team at under 12 level, there was no pathway for those girls after that. There had never been a section in the club just for girls and none of us knew the first thing about how to keep these young girls playing football. Initially, the aim was just to keep them active and part of the social life of the club, but of course we soon realised that they couldn't keep playing and enjoying football unless more girls started playing with them. So, we linked up with the LGFA and the local national school to begin the task of encouraging more girls to play football.

In those first months, we cobbled together an under 13 team and entered the bottom rung of the county league. Within six years we managed to grow the section enough to field teams all the way up to minor, and to join with a neighbouring club to form a fledgling adult team.

This was my first real experience of being involved with female sport. Even though I literally just fell into it, it quickly became apparent how difficult a journey it was going to be. It was my first time to fully appreciate the prejudices that had to be overcome for a young girl to play the same sports in the same places as the young boys in their age group. All the natural progressions for young boys into sport are so deeply ingrained in us that we don't have to think about what we are doing to provide a proper pathway for them. Each step on their journey is facilitated easily, it is a natural progression in terms of opportunities, coaching, facilities and all that.

There are far more opportunities for girls to engage with sport now than ever before, and studies have shown that the gender gap in participation is thankfully narrowing. Yet many of the old obstacles remain. More girls drop out of sport in their teenage years than boys; more teenage girls than boys drop out of sport in the year of the two big State exams; 
and the pattern continues into adulthood. It seems that on every step of life's journey the odds remain more against females becoming involved in sport, or staying involved in sport.

The Growing Up In Ireland project, which has been tracking the lives of thousands of children born in 1998, has been very revealing. More than one quarter of Ireland's 17- and 18-year-olds are too heavy, and more girls than boys are overweight ( 30 per cent against 25 per cent). Two-thirds of teenagers are getting the recommended amount of exercise each week, that is, 150 minutes of moderate to vigorous activity, but the difference is stark when you look at the gender split: 76 per cent of boys are getting the recommended amount, while just over half of girls are. I heard recently about an all-girls school in a large county town which this year did not timetable Physical Education (PE) for its Leaving Cert students. The school (like many) also shortened its lunch break time because of Covid-19, so there is no opportunity for sixth year girls to exercise during their school day.

In coaching teams, I saw first-hand the kind of prejudices which are holding girls back. Parents who were not supportive of their daughters playing a sport; schools not providing proper physical education for girls; coaches trying to get access to pitches for training sessions and games; women feeling reluctant to come forward for coaching and administrator roles because of a lack of encouragement and mentoring . . As someone who played sport, was an administrator at club and county level, and whose chosen professional career was wrapped up in sport, I was challenged to see it from a different perspective by what I was experiencing.

When, in 2017, the Irish women's soccer team had to change out of their tracksuits in the toilets at Dublin Airport and hand them back to FAI officials after returning from international duty, there was a storm of criticism. But this is the kind of ritual humiliation so many girls and women experience week in and week out.

It took time, but what I was learning as a volunteer opened my eyes to my own failures in my role as a sports editor to face up to the newspaper's responsibilities. And it wasn't just enough to write about the problems I was encountering - the women and the games and the events needed to be properly addressed and covered too. After all, by the first decade of the twenty-first century change was still dripping slowly in the national media, even though the level - and quantity - of the action was on the increase. So too was the quality. Critically, a number of women were also making an impact in the sports media, in print and on air.

That first camogie supplement broke through the glass ceiling. Prior to that, the Sunday Independent had tipped the hat every now and then to women in sport, trying to ensure that any big event or story was not missed. In 2017, the Sunday Independent produced two four-page wraparounds, one for the camogie finals and the other for the ladies' football finals. In subsequent years, these special publications on the two finals' days continued and became more confident in how they portrayed the occasions. The days themselves also became more noteworthy as more and more people attended or watched on television. The 2019 ladies football finals attracted just over 56,000 to Croke Park, making it second only that year to the FIFA's Women's World Cup final for attendance at a women's sporting event.

Ladies football and camogie are two of the success stories of Irish women's sport because of the levels of participation in the games on the ground. Football, in particular, has thrived across all 32 counties. But they have also been hugely successful in another area - in penetrating the national media by engaging directly with decision makers. Furthermore, they have brilliantly exploited the phenomenal growth in coverage of the men's games of Gaelic 
football and hurling to ensure increased coverage of their own sports. Both Ladies Gaelic football and camogie are now very much a part of the television coverage of the GAA family of games, through the national broadcaster RTE and its Irish language partner, TG4. (In fact, the big four - Ladies football, camogie, rugby and soccer - all dramatically improved their communications with media outlets, including supplying their own material for use in the media.)

In general, though, women's sport still lags some way behind when it comes to participation, attendance and media coverage. And day to day coverage of women's sport is still not where it should be. Research published at the conclusion of the 20x20 movement - a two-year campaign to achieve greater visibility for women's sport - showed that just five per cent of sport's online coverage and six per cent of sport's print coverage was dedicated to women's sport. Furthermore, there was a significant decline of over 40 per cent in television coverage over the two-year period of the campaign, even though the output from RTE and TG4 increased, as did the audience. This shows the impact of external broadcasters (mainly from the UK) on the Irish landscape, arguably increasing the responsibility on native media outlets.

As Sarah Colgan, co-founder of 20x20, observed: "There is still a huge way to go to get to 50/50, and we are coming from a terribly low base, but the responsibility and the opportunity for everyone touching sport is huge now. We all need to set expectations high when it comes to women's sport, to keep pushing for answers and questioning ourselves and what we see around us in order build on this momentum." 